\title{
Pain from intramuscular vaccine injection in adults
}

\author{
FRANCIS SAHNGUN NAHM ${ }^{1}$, PYUNG BOK LEE ${ }^{1}$, SOO YOUNG PARK ${ }^{2}$, \\ YONG CHUL KIM ${ }^{2}$, SANG CHUL LEE ${ }^{2}$, HWA YONG SHIN ${ }^{3}$, CHUL JOONG LEE ${ }^{4}$
}

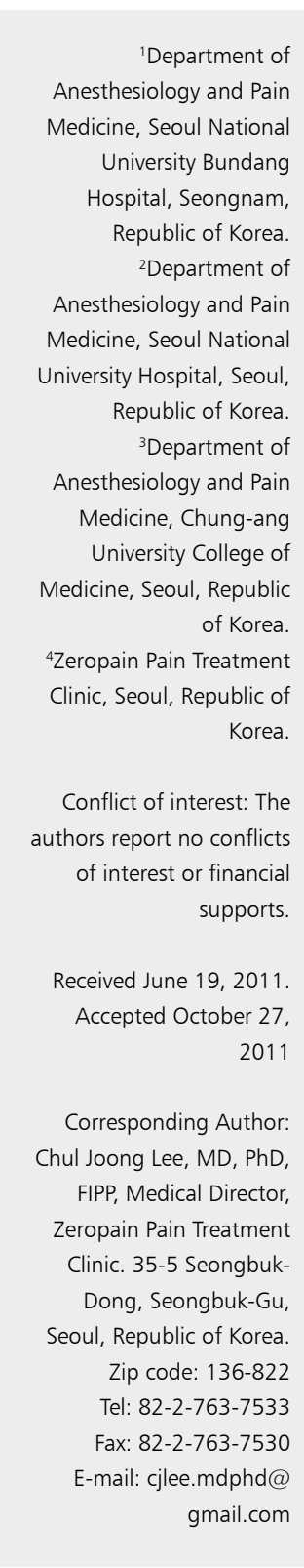

\begin{abstract}
Background: Vaccine use has been increasing worldwide, and adult populations are presented with more opportunities to experience pain from vaccine injection. The insertion of a needle through the skin is the most common source of iatrogenic pain, and needle phobia is a major concern in medical practice. However, it is unclear which factors play major roles in the perception of pain from vaccine injection in adults. Aim: To evaluate the influences of patient characteristics on pain perception due to intramuscular vaccine injection in healthy adult volunteers. Material and Methods: The injection of hepatitis B vaccine using a $24 \mathrm{~mm}, 24-G$ needle was performed as a uniform stimulus, and the intensity of injection pain was measured immediately after the injection using a 100-mm visual analogue scale (VAS). The influences of patient characteristics on pain intensity were investigated. Results: One hundred sixty volunteers ( 65 males, 95 females) were enrolled in this study. The average VAS score was $20.8 \pm 17.1$ (range 0 to 67) in males and $34.4 \pm 19.7$ (range 2 to 76 ) in females $(P<0.001)$. However, there were no correlations between VAS score and age, body mass index or maximal pain score from previous painful experiences. The VAS score was also not affected by the experience of previous vaccine injections, a history of childbirth in females, or religion. Conclusions: Gender appears to be the only major factor that influences the pain of intramuscular vaccine injection. Therefore, pain-reducing methods will be needed when performing injection procedures, particularly in women.
\end{abstract}

(Rev Med Chile 2012; 140: 192-197).

Key words: Injections, intramuscular; Gender; Needles; Pain; Vaccination.

\section{Percepción de dolor después de una inyección intramuscular en adultos}

Antecedentes: La inserción de una aguja para inyecciones es la forma más común de inducción de dolor iatrogénico. No se sabe qué factores afectan la percepción del dolor. Objetivo: Evaluar la influencia de características propias de los pacientes en la percepción de dolor después de una inyección intramuscular. Material y Métodos: Se utilizó como estímulo, la inyección intramuscular de vacuna de hepatitis $B$, mediante una aguja de $24 \mathrm{~mm}(24 \mathrm{G})$. La intensidad del dolor fue evaluada inmediatamente después de la inyección utilizando una escala visual análoga de $100 \mathrm{~mm}$ (VAS). Se evaluó la influencia de las características de los pacientes en la intensidad del dolor. Resultados: Participaron 160 voluntarios (65 hombres). El puntaje VAS fue 20,8 \pm 17,1 (rango 0 a 67) en hombres y 34,4 $\pm 19,7$ (rango 2 a 76 ) en mujeres $(p<0,01$ ). No hubo asociación entre el puntaje VAS y edad, indice de masa corporal, haber experimentado previamente dolor, haber dado a luz en mujeres o religión. Conclusiones: El género es la única variable que se asocia con la percepción de dolor después de una inyección intramuscular. 
$\Lambda$ lthough the use of vaccines for the prevention of infectious diseases has primarily focused on vaccination of children, the recent pandemic spread of novel influenza and the development of novel vaccines against herpes zoster ${ }^{1}$ and cervical cancer ${ }^{2}$ have led to increased use of vaccines in the adult population. Adequate vaccinations for preventable diseases are recommended for health care workers or persons at increased risk of complications from the diseases. ${ }^{3}$ As a result, adults have been provided with more opportunities for vaccination than existed in the past.

Needle insertion through the skin is the most common source of iatrogenic pain, and 'needlephobia' can seriously compromise medical care. There have been several efforts to reduce needleinduced pain or distress ${ }^{4,5}$. However, even if a uniform nociceptive stimulus is applied, individuals may complain of pain to varying degrees because pain is a subjective experience to a noxious stimulus and many individual factors contribute to pain perception. For this reason, the objective quantification of individual pain intensity and identification of the factors influencing pain perception are very important for the ultimate reduction of pain in medical practice.

There have been several studies on vaccinerelated pain in children, but few such studies have been conducted in adults. Numerous studies have examined the individual factors influencing pain perception using thermal, ${ }^{6-9}$ cold pressor, ${ }^{10,11}$ mechanical, ${ }^{12}$ ischemic, ${ }^{13,14}$ chemical ${ }^{15,16}$ or electrical $^{17-19}$ stimuli to provoke pain. However, these studies have limitations for clinical application because they were either laboratory-based or used only noninvasive noxious stimuli. Furthermore, the results of these studies were inconsistent and depended on the pain provocation method. Consequently, these studies have limitations to actual clinical applications involving vaccine-injection pain in adults. The purpose of our study was to identify which patient characteristics represent the main influence on pain perception during intramuscular (IM) vaccine injection in adults.

\section{Material and Methods}

\section{Study subjects}

Study approval was obtained from our institutional review board (IRB No. H-0806-074-248), and all participants provided written informed consent. This study was carried out on healthy Korean volunteers who were older than 20 years and who visited the public health center for hepatitis B vaccination from February 2006 to February 2007.

The exclusion criteria included participants with peripheral neuropathy; participants taking medications that might interfere with pain perception; and those who were unable to understand the visual analogue scale (VAS) for pain.

\section{Pain provocation method}

Uniform IM injections of all study participants were carried out with a hepatitis B vaccine (Euvax', LG Life Science, Ltd., Korea) using a $24 \mathrm{~mm}, 24-\mathrm{G}$ needle (Unibody ${ }^{\oplus}$ Becton Dickinson Korea, Ltd., Korea). The skin was prepared with a 70\% isopropyl alcohol-soaked cotton swab for 10 seconds, followed by an injection of $1 \mathrm{~mL}$ of vaccine into the deltoid muscle of the non-dominant arm by a single female nurse.

\section{Pain assessment}

Prior to the injection, one male doctor explained the 100-mm VAS for pain and obtained informed consent from each patient. Immediately after the injection, the subjects were asked to report to the same doctor their maximal pain intensity during the injection in the absence of the nurse who performed the injection. The following demographic data was recorded: age, gender, height, weight, number of previous hepatitis B vaccinations, childbirth history, religion and the maximal pain score of any previous experiences such as trauma or surgery.

\section{Statistical analysis}

A pilot study showed a gender allocation ratio of males/females of 0.75 and a mean difference in the VAS score between genders of 12, with a standard deviation of 19. According to the pilot study, the required sample size was 47 for the male group and 61 for the female group under alpha $=$ 0.05 and beta $=0.10$.

Statistical evaluation was carried out using an independent Student's t-test, one way analysis of variance, Pearson's correlation analysis or analysis of covariance (ANCOVA). P-values of less than 0.05 were considered statistically significant. All values are presented as the mean \pm standard deviation. 


\section{Results}

\section{Patient characteristics}

One hundred sixty participants, 65 males and 95 females, were enrolled in this study (Table 1 ). The average age was $32.0 \pm 11.0$ years (range 20 to 64 years, median 31 years) and the average body mass index (BMI) was $22.4 \pm 3.37 \mathrm{~kg} / \mathrm{m}^{2}$ (range 15.24 to $32.39 \mathrm{~kg} / \mathrm{m}^{2}$ ). There were no statistical differences with regard to age, number of previous hepatitis B vaccine injections, religion or maximal pain score of any previous experience between the male and female subjects. However, there was a difference in body mass index (BMI) between genders $(P<0.001)$, which was considered a co-variable when performing the ANCOVA.

\section{Relationships between patient characteristics and VAS score}

The average VAS score was $28.9 \pm 19.8$ (range 0 to 76 , Figure 1). The VAS score of males and females was $20.8 \pm 17.1$ (range 0 to 67 ) and $34.4 \pm$ 19.7 (range 2 to 76 ), respectively. Females reported a significantly higher VAS score for a uniform invasive stimulus compared to that of males $(P<0.001$, Figure 2). The number of previous hepatitis $B$ vaccinations $(P=0.29)$, the experience of labor pain $(P=0.25)$, and religion $(P=0.28)$ did not affect the VAS score (Table 2).

Pearson's correlation analyses showed that neither age $(r=0.03, P=0.74)$, BMI $(r=-0.22$, $P=0.089$ ) nor the maximal pain score of any previous experiences $(r=0.21, P=0.076)$ influenced the perception of pain (Table 3 ).

Table 1. Subject characteristics

\begin{tabular}{|lllll|}
\hline & Male & Female & Overall & P-value \\
Number of participants & 65 & 95 & 160 & NA \\
Age (years) & $33.5 \pm 10.8$ & $31.0 \pm 11.0$ & $32.0 \pm 11.0$ & 0.17 \\
Body mass index (kg/m2) & $24.6 \pm 3.05$ & $20.6 \pm 2.38$ & $22.4 \pm 3.37$ & $<0.001$ \\
Religion (Yes/No/No answer) & $27 / 32 / 6$ & $39 / 40 / 16$ & $66 / 72 / 22$ & 0.36 \\
$\begin{array}{l}\text { Number of previous } \\
\text { hepatitis B vaccinations (0/1/2) }\end{array}$ & $36 / 17 / 12$ & $39 / 33 / 23$ & $75 / 50 / 35$ & 0.20 \\
Experience of labor pain (Yes/No) & $\mathrm{NA}$ & & & $\mathrm{NA}$ \\
Maximal pain score of previous experience & $79.2 \pm 18.1$ & $81.3 \pm 18.0$ & $80.4 \pm 18.0$ & 0.62 \\
\hline
\end{tabular}

Values are mean \pm standard deviation or number of participants. NA, not assessed.

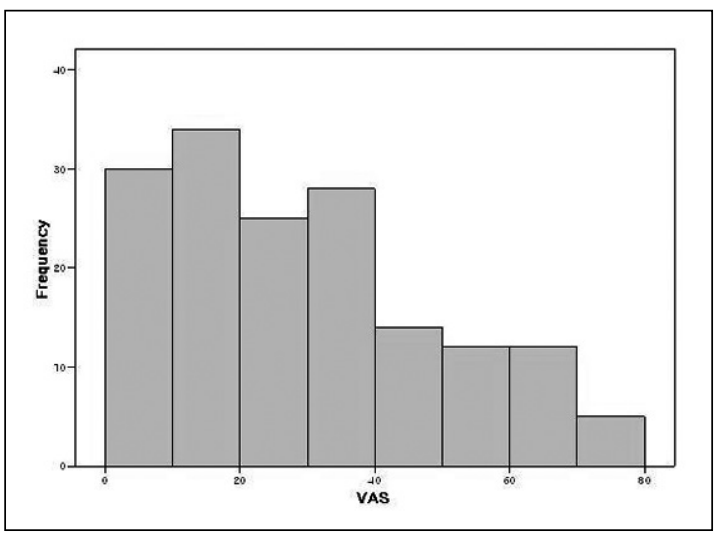

Figure 1. Histogram of VAS sores. The overall VAS score of all participants was $28.9 \pm 19.8$ (mean \pm standard deviation).

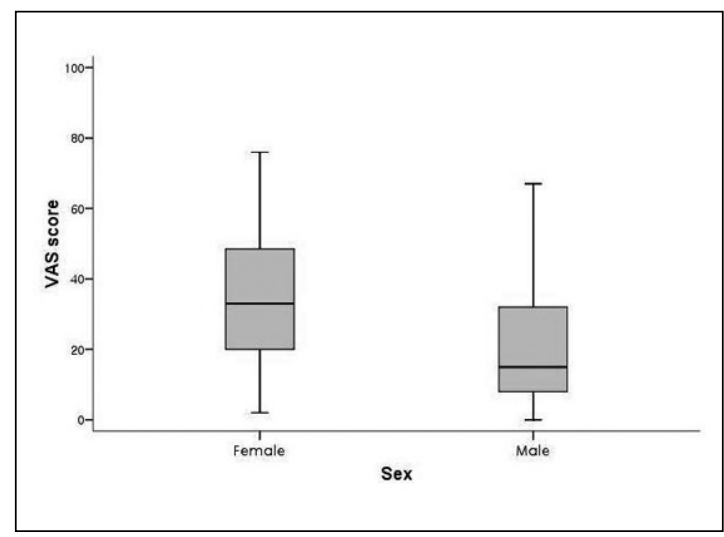

Figure 2. Boxplot of VAS scores. Females reported a higher mean VAS score than did males $(P<0.001)$. 
Intramuscular injection pain - F. Sahngun Nahm et al

Table 2. Visual analogue scale (VAS) scores for categorical variables

\begin{tabular}{|llll|}
\hline & & VAS score & P-value \\
Gender & Overall & $28.9 \pm 19.8$ & $<0.001$ \\
& Male & $20.8 \pm 17.1$ & \\
& Female & $34.4 \pm 19.7$ & \\
Repeated number of & 0 & $26.7 \pm 18.3$ & 0.29 \\
vaccinations & 1 & $29.3 \pm 18.7$ & \\
& 2 & $33.0 \pm 23.9$ & \\
Labor pain* & Yes & $32.1 \pm 16.4$ & 0.25 \\
& No & $36.8 \pm 22.5$ & \\
Religious & Yes & $27.5 \pm 17.5$ & 0.28 \\
& No & $31.1 \pm 20.4$ & \\
\hline
\end{tabular}

Only gender showed statistical significance on the VAS score. $\mathrm{NA}$, not assessed; N-S, nonspecific. *Evaluated in female participants

Table 3. Correlation coefficients between continuous variables and VAS scores

\begin{tabular}{|lcc|}
\hline & $\begin{array}{c}\text { Pearson's } \\
\text { correlation } \\
\text { coefficient } \\
\text { (r) }\end{array}$ & P-value \\
\hline Age & 0.03 & 0.74 \\
Body mass index & -0.22 & 0.089 \\
$\begin{array}{l}\text { Maximal pain score of } \\
\text { previous experience }\end{array}$ & 0.21 & 0.076 \\
\hline
\end{tabular}

\section{Discussion and conclusions}

In this study, we attempted to identify patient characteristics that may influence the perception of pain in actual clinical situations of IM vaccine injection. The results revealed gender to be the major factor that influenced the perception of pain. The effect size of this study was 0.69 , which implies a moderate to large difference in pain perception between genders. This result is in agreement with those of previous studies ${ }^{7,14,16}$ that consistently demonstrated that females are more sensitive to pain than are males. This phenomenon could be explained by physiological and psychological gender differences. Men may have stronger $\mu$-opioid systems than women ${ }^{16}$, although the contribution of pain processing at the spinal level also differs between males and females ${ }^{18}$. In addition, there are gender differences in cognitive-affective factors of pain response ${ }^{10}$. Furthermore, cultural factors may be involved, such as the education of males to have a stoic attitude and to underreport pain. ${ }^{20}$ Gender differences in pain perception are thought to be influenced by a combination of these factors.

We did not observe any age effect on pain perception. The results of previous studies on age-related differences in response to experimental noxious stimuli are equivocal and inconsistent according to the pain-inducing methods. Lautenbacher et $\mathrm{al}^{8}$ reported that the thresholds for non-noxious stimuli increase with age, whereas the pressure pain thresholds decrease, although the heat pain threshold showed no age-related changes. Pickering et $\mathrm{al}^{9}$ reported that pressure nociception decreases with age especially in males, while thermal thresholds are not modified. In addition, relative decreases were observed in the frequency and intensity of pain associated with visceral disease, musculoskeletal conditions, and malignancies in adults of advanced age ${ }^{21}$. Our study was limited to the evaluation of the age effect on pain perception since only one person was over the age of 60 and no pediatric participants were recruited. Further studies will be needed to compare differences in pain perception for a uniform invasive stimulus according to age.

Limited information is available on how a previous pain experience influences pain perception. In this study, pain perception was not influenced by a previously-experienced maximal pain score, the number of experienced vaccinations or the experience of labor pain. This suggests that previous pain experience does not influence pain perception.

We found no relationship between religion and VAS score. In a previous study of patients with cancer pain, religion was associated with a significantly lower prevalence of depression but was not related to the intensity of pain perception. ${ }^{22}$ Another study carried out in patients with musculoskeletal pain showed that religion/spirituality was not related to pain intensity or life interference caused by pain ${ }^{23}$. Our results are consistent with these studies, even though our study was carried out in an acute pain setting.

BMI did not influence the VAS score in our 
study. In a previous study, in which electrical stimulation was applied to evoke pain, body size was the only significant factor that correlated with electrical sensitivity, ${ }^{17}$ although the precise mechanism was unclear. Unlike our study, that previous study was based on non-invasive pain from electrical stimulation. Our findings suggest that BMI does not influence pain perception when applied invasively, as opposed to superficially applied pain.

Our study has several advantages for evaluating the factors that influence pain perception. The degree of maximal pain was assessed during an intramuscular injection for vaccination using a $24 \mathrm{~mm}$, $24-G$ needle. The insertion of a needle through the skin is the most common source of iatrogenic pain in hospitals and a frequently encountered aversive stimulation during medical procedures. Therefore, this situation more accurately reflects real life than does laboratory-based non-invasive pain for the evaluation of factors related to pain perception. Another advantage of our pain-evoking method is that it produces a uniform noxious stimulus to all participants, unlike the control subjects of other clinical studies.

However, this study had some limitations. First, it did not reflect chronic pain. Although the stimulus applied to the participants was closer to a clinical situation than laboratory-based noxious stimuli, it still involved the pain from a single vaccine injection. The pain from injection was very brief and stimulated a very small anatomical region. In contrast, most forms of clinical pain are longer lasting and affect larger body areas. Second, the intensity of the noxious stimulus was low. The average VAS score indicated mild pain for most participants, which may not be the ideal stimulus for investigating individual differences. Although an intensity that was at least moderate would have been preferable for evaluating the relationship between patient characteristics and invasive noxious stimuli, the application of such a degree of invasive pain is discouraged due to ethical considerations. Third, the indirect VAS was used to quantify pain intensity. Although the VAS is one of the most widely and frequently used methods to quantify the intensity of pain due to its high validity and consistency ${ }^{24}$, it remains an indirect measure. Actual pain sensation may not be reflected directly by the expression of the intensity of pain. However, no other methods to directly measure subjective pain sensation are currently available. Therefore, an indirect method of quantifying the intensity of pain is the only choice. Fourth, our study did not consider other variables that could also have influenced pain perception such as mood status, level of education, marital status, and socio-economical status of the participants. Further studies will be needed to determine the effects of these variables when applying a uniform stimulus. Finally, this study included only one person over the age of sixty. Consequently, it could only reflect age effects for young and middle-aged people.

In conclusion, gender is a significant predictor of pain perception due to invasive stimulation. Other factors such as age, body mass index, previous pain experience, number of vaccine injections, childbirth history and religion did not affect the pain perception. Therefore, various methods like topical anesthetics or vapocoolant spray should be used to reduce the intensity of pain when performing invasive procedures, particularly in women.

\section{References}

1. Kimberlin DW, Whitley RJ. Varicella-zoster vaccine for the prevention of herpes zoster. N Engl J Med 2007; 356: 1338-43.

2. Broomall EM, Reynolds SM, Jacobson RM. Epidemiology, clinical manifestations, and recent advances in vaccination against human papillomavirus. Postgrad Med 2010; 122: 121-9.

3. Harpaz R, Ortega-Sánchez IR, Seward JF; Advisory Committee on Immunization Practices (ACIP) Centers for Disease Control and Prevention (CDC). Prevention of herpes zoster: recommendations of the Advisory Committee on Immunization Practices (ACIP). MMWR Recomm Rep 2008; 57: 1-30; quiz CE32-34.

4. Kettwich SC, Sibbett WL, Kettwich LG, Palmer CJ, Draeger HT, Bankhurst AD. Patients with needle phobia? Try stress-reducing medical devices. J Fam Pract 2006; 55: 697-700.

5. Hartstein BH, Barry JD. Mitigation of pain during intravenous catheter placement using a topical skin coolant in the emergency department. Emerg Med J 2008; 25: 257-61.

6. Al'Absi M, Wittmers LE, Ellestad D, Nordehn G, Kim SW, Kirschbaum C, et al. Sex differences in pain and hypothalamic-pituitary-adrenocortical responses to opioid blockade. Psychosom Med 2004; 66: 198-206.

7. Feine JS, Bushnell MC, Miron D, Duncan GH. Sex di- 
fferences in the perception of noxious heat stimuli. Pain 1991; 44: 255-62.

8. Lautenbacher S, Kunz M, Strate P, Nielsen J, ArendtNielsen L. Age effects on pain thresholds, temporal summation and spatial summation of heat and pressure pain. Pain 2005; 115: 410-8.

9. Pickering G, Jourdan D, Eschalier A, Dubray C. Impact of age, gender and cognitive functioning on pain perception. Gerontology 2002; 48: 112-8.

10. Jones A, Zachariae R. Investigation of the interactive effects of gender and psychological factors on pain response. Br J Health Psychol 2004; 9: 405-18.

11. Zimmer C, Basler HD, Vedder H, Lautenbacher S. Sex differences in cortisol response to noxious stress. Clin J Pain 2003; 19: 233-9.

12. Sarlani E, Grace EG, Reynolds MA, Greenspan JD. Sex differences in temporal summation of pain and aftersensations following repetitive noxious mechanical stimulation. Pain 2004; 109: 115-23.

13. Fillingim RB, Ness TJ, Glover TL, Campbell CM, Hastie BA, Price DD, et al. Morphine responses and experimental pain: sex differences in side effects and cardiovascular responses but not analgesia. J Pain 2005; 6: 116-24.

14. Maixner W, Humphrey C. Gender differences in pain and cardiovascular responses to forearm ischemia. Clin J Pain 1993; 9: 16-25.

15. Baad-Hansen L, Poulsen HF, Jensen HM, Svensson P. Lack of sex differences in modulation of experimental intraoral pain by diffuse noxious inhibitory controls (DNIC). Pain 2005; 116: 359-65.

16. Zubieta JK, Smith YR, Bueller JA, Xu Y, Kilbourn MR,
Jewett DM, et al. Mu-opioid receptor-mediated antinociceptive responses differ in men and women. J Neurosci 2002; 22: 5100-7.

17. Larkin WD, Reilly JP, Kittler LB. Individual differences in sensitivity to transient electrocutaneous stimulation. IEEE Trans Biomed Eng 1986; 33: 495-504.

18. Mylius V, Kunz M, Schepelmann K, Lautenbacher S. Sex differences in nociceptive withdrawal reflex and pain perception. Somatosens Mot Res 2005; 22: 207-11.

19. Walker JS, Carmody JJ. Experimental pain in healthy human subjects: gender differences in nociception and in response to ibuprofen. Anesth Analg 1998; 86: 1257 62.

20. Otto MW, Dougher MJ. Sex differences and personality factors in responsivity to pain. Percept Mot Skills 1985; 61: 383-90.

21. Gibson SJ, Helme RD. Age-related differences in pain perception and report. Clin Geriatr Med 2001; 17: 43356, v-vi.

22. Aukst-Margetic B, Jakovljevic M, Margetic B, Biscan M, Samija M. Religiosity, depression and pain in patients with breast cancer. Gen Hosp Psychiatry 2005; 27: 250-5.

23. Rippentrop EA, Altmaier EM, Chen JJ, Found EM, Keffala VJ. The relationship between religion/spirituality and physical health, mental health, and pain in a chronic pain population. Pain 2005; 116: 311-21.

24. Lara-Munoz C, De Leon SP, Feinstein AR, Puente A, Wells CK. Comparison of three rating scales for measuring subjective phenomena in clinical research. I. Use of experimentally controlled auditory stimuli. Arch Med Res 2004; 35: 43-8. 